\title{
Modelling fuel consumption and refuelling of autonomous vehicles
}

\author{
Máté Zöldy* and Imre Zsombók ${ }^{1, *}$ \\ ${ }^{1}$ BME Budapest University of Technology and Economics, Department of Automotive Technologies, Budapest Stoczek u. 6.
}

\begin{abstract}
In our research we highlighted the problematic of the refuelling of autonomous vehicles. During the way to be full autonomous, the vehicles take over more and more driving function from the driver. It is lot of focus on automotive cyber security or trajectory following, but refuelling is not in the main researches. After reviewing the vehicle drivetrains, it was specified which to focus for further testing. In the second part of the article the main influencers of fuel consumption was listed based on a literature overview. Main aspects of the carried out test is listed and results helped us to refine the research direction. For modelling the refuelling of the vehicle it is an enabler to set realistic models for fuel consumption. Relevant researches were studied and these was extended with overview of refuelling studies. Based on these the main direction of our research was set.
\end{abstract}

\section{Introduction}

Autonomous vehicles are more than more part of our everyday life in Europe. It has been started with driving and brake assistants, but nowadays it is common that a vehicle can manage the parking alone or helps to solve a takeover situation $[17,22]$. As it is in technical and tabloid news as well, manufacturer's after each other announcing more and more feature containing vehicles. Some of these vehicles are on traditional internal combustion engine basis, some others are using hybrid technology and certainly full electric cars are available as well.

In our research our aim is to work out, simulate and test a decision making system supported with artificial intelligence to optimize autonomous vehicles refuelling. In this paper the first problem definition is presented.

\section{Vehicle propulsions and refuelling}

For long time it was not to mention the drivetrain system, the main difference was about the fuel: vehicle was operated with diesel or gasoline. Nowadays the situation is more complex, first hybrids, than plug-inhybrids latest electric drivetrains arrived.

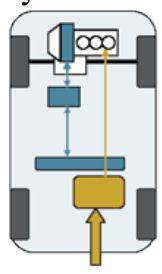

Parallel HEV

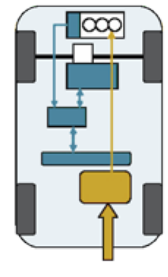

Series HEV

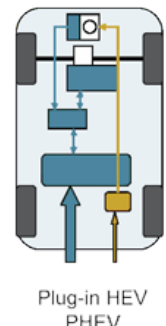

PHEV

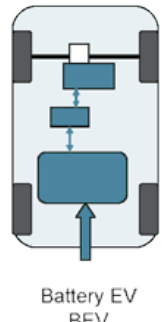

BEV
1. Figure New automotive drivetrains [7]
As Figure 1 shows parallel and series hybrids are more closer to the traditional internal combustion engine (ICE). With orange it is to see the refuelling with conventional fuel. In case of Plug-in Hybrid Electric Vehicles (Plug-in HEV or PHEV) first appears the external electric recharging option. These vehicles, as it can be followed at Figure 1 can be refuelled with conventional fuel and parallel to that with electricity. Battery electric vehicles (BEV) are rechargeable only with electricity, they are disconnected to fossil fuels.

\subsection{Internal combustion engine}

Conventional spark ignition and compression ignition engines, as called together internal combustion engines are part of mobility since 1876. In this year invented Nicolaus Otto four-stroke spark ignition engine. First engines was constructed for alternative fuels: gases and vegetable oils. They had four strokes: it carries out four piston strokes during a combustion cycle. Design of spark ignition engines was changed a lot during the years.

History of diesel started a bit later and the main difference is in combustion start: diesel engines uses the compression to start the combustion in the chamber. Daimler designed the first engine according to this principle.

Traditional combustion engines, independently if it is fuelled by diesel, gasoline, liquid or even gaseous alternative fuels. Most of the vehicles on the road today are very similar from drivetrain point of view. Lot of development happened during the decades and thanks for that today's internal combustion engines have considerably better efficiency, have better emission characteristic than those from decades ago, the basic

*Corresponding author: mate.zoldy@auto.bme.hu 
theory to combust fuel to create power remains the same $[20,21]$.

Refuelling of internal combustion engine is managed most of the cases in refuelling stations. They have fixed locations along the roads, they are mainly settled according to customer demand. Near to fuel they could offer extra services, as food, store, relax zone etc. Vehicles has a fuel sensor that measures the remaining fuel level in the tank. The signal of this sensor is placed into the driver's dashboard and gives virtual feedback. In older models driver see the remaining fuel level a based on that the decision was made to stop for refuelling. In modern vehicles there is a calculation based on the last mileages driving behaviour and its predicts how many kilometres can be driven with the car until the tank will be empty.

\subsection{Hybrid Drivetrains}

In first view hybrids seems to be the first and strongest alternatives of internal combustion engines. After a Japanese manufacturer puts his first hybrid vehicles into series, most of the manufacturers have hybrid models. If it is checked in detail, hybrids are more a good tool to reduce fuel consumption of traditional engines instead of replace them. Mechanical setup of hybrid electric vehicles could differ a lot, fundamentally all hybrids have a mixed electric motor and internal combustion engine drivetrain and an electric battery, where either or both combustion engine and the electric motor could power the drivetrain. Batteries could be recharged in several ways, as be spanned by a generator when traditional engine is operating or in some cases, kinetic energy of the vehicle can be converted into electric energy with the help of systems like regenerative brakes.

The refuelling of these hybrids are very similar to ICE vehicles, while they are using as primarily energy source mainly gasoline and or diesel. Electricity is generated on board so it is not needed to refuelled outside. Optimization of utilization of conventional fuel and electricity is decided in motor management system.

\subsection{Plug-in hybrid electric vehicles}

Plug-in hybrid vehicles have a lot of similarities with hybrid electric vehicles as their drivetrain is hybrid: both have a traditional combustion engine and electric motor. The difference to hybrid vehicles, that these batteries can be recharged by plugging it in to a power source. When the battery is depleted, the plug-in hybrid starts acting as a regular hybrid, with the combustion engine taking the role of primary power source.

Energy management of plug-in-hybrid electric vehicles enables a much broader optimization scale. It includes the traditional opportunities and setup of traditional engines and has the option to refuel the battery. Battery refuelling nowadays has three main options. First is the charging facilities placed into traditional fuel stations. These are easy to find, loading level can be various, depending on the generation of the charger. There are standalone chargers as well mostly in city centres in parking places or park zones of hypermarkets. Most of the cases the waiting for free charger is not solved. Third option is charging home at residential areas or some workplaces are also offering such option. The public availability of both these charging types are limited.

\subsection{Battery electric vehicles}

This type of vehicles are the first in this summary, those do not have internal combustion engine. They run on a fully electric with rechargeable battery. These vehicles can be recharged by be plugged into a power source. Recharging time and driving ranges are varying depending on the type of the vehicle.

Recharging options of battery electric vehicles are covered with the options of plug-in-hybrid electric vehicles.

Table 1. Refueling possibilities of different drivetrains

\begin{tabular}{|l|l|l|l|l|}
\hline refuel & ICE & HEV & PHEV & BEV \\
\hline fuel & yes & yes & yes & no \\
\hline electricity & no & no & yes & no \\
\hline
\end{tabular}

Based on the complexity of the refuelling of plug-inhybrid technology, as it summarized in Table 1 , it is worth to put it in the focus of our research. Our modelling will focus on this drivetrain and as it contains the solutions for pure ICE and pure electric vehicles as well, results will be easily convertible to these.

\section{Fuel consumption Influencers}

Increasing fuel prices growing need for more efficient vehicles resulted that fuel consumption has become one of the key challenges of the vehicle industry. Control of fuel consumption and its maintenance an average level requested lot of new solutions to be introduced. These solutions are covering energy optimized planning of routes, support and training of drivers, autonomous or partially autonomous vehicles, intelligent fleet management and platooning. To able to develop highly automated self-driving vehicles the basics of fuel consumption have to be understood. It is also a great opportunity to understand and utilized in an increased way the driver assist systems for eco-driving. This also provides a great help in assisting drivers in eco-driving training. Vehicles fuel- and energy consumption could depend on various different reasons and that are to be categorized as,

1 vehicle driven parameters,

2 road related parameters,

3 usage (driver) related parameters,

4 ambient parameters [1].

\subsection{Vehicle driven parameters}

Vehicle driven parameters are the physical attributes of vehicle like its length and weight, gearbox, type of the engine and motor, vehicle type, etc.

Vehicle fuel efficiency related questions as if an engine is not maintenance properly are also incorporated in this, as they could influence engine fuel efficiency, it will lead to a decline in the engine's fuel efficiency. 
Simple maintenance activities such as regular, in time changes of oil and oil filters, change of air-filters, and intime replacement of spark plug will increase vehicle lifespan and parallel they will improve vehicle fuel economy. In contrary missing to change worn out spark plugs, elements of air cleaner system or fuel filters as well as improper maintenance of throttle valves or oxygen sensors will effect fuel consumption increase.

Engine oil quality is also having an impact on fuel economy of the vehicle. In case of non-standard engine oil utilisation, at certain loads and temperatures, pistons of the engine and other moving parts freedom of moving will be lower. It increases the load on engine and it results increased fuel consumption.

Condition of tires is an important factor to manage the fuel consumption. If the tire pressure is too low, then vehicle needs more energy from the engine for efficient move around. It is important to keep the pressure barriers proposed by manufacturers.

\subsection{Road related parameters}

Road has several parameters that have influence on fuel consumption. Several test was conducted to investigate relationship between road surface type and the rolling resistance of vehicles. A excessive knowledge database has been created on the low-noise road surfaces interconnection with a lower rolling resistance and how it can be a good tool to decreasing vehicles fuel consumption and carbon-dioxide emissions [2, 23]. Research results demonstrated for lightweight vehicles a rolling resistance decrease up to $10 \%$ in case when fuel economy of driving on a double-layered highly porous asphalt road surface was compared to a regular highly porous surface. This $10 \%$ decrease in rolling resistance is equivalent to a $2-3 \%$ reduction fuel consumption and as well in carbon-dioxide emissions. It doesn't seems to be a huge amount but if it is multiplied with the total distance of the vehicles, than it is easy to calculate that it represents an amazing amount of fuel saving per annum [2]. Not only the road surface but construction material of the road have effect on fuel consumption. New materials, as rubber bitumen have a positive effect on vehicles fuel consumption [3].

\subsection{Usage related parameters}

Vehicle utilisation parameters or operational is nowadays stored in fleet management systems and it gives an easy opportunity to reach and to analyse. Database could contain different data types related to the vehicle as id of the vehicle, odometer actual value, total runtime, vehicle speed, severe accelerations, number and intensity of brakes, over speeding, etc.

Driving behaviour or style of the driver also have huge effect on fuel consumption. Aggressive driving and inappropriate gear handling are the most common ways to keep engine in high revolution areas that results extra fuel consumption. Keeping the right distance between the vehicles result lower number of unnecessary brakes and

through that it improves fuel consumption. Automatic transmission systems could compensate this for a defined range, while these are quicker in the shift up. This mostly applies to manual cars because automatic transmissions shift up more quickly. Definite speeds are proposed to be driven in given gears. For example, if vehicle runs at $90 \mathrm{~km} / \mathrm{h}$ in fourth gear, then vehicle will need more energy to be moved in comparison to driving at same speed in fifth gear, and it will result extra fuel consumption.

Planning and optimising routes has effect fuel consumption. From fuel efficiency point of view, the two neuralgic point are the start-up of the vehicle and short trips. One of the reasons behind this phenomenon is that catalytic converters (that are used to decrease the emitted air pollutants) cannot be operated in a proper way until they reach the utilization temperature. The border is around 5-6 km; under this distance the internal combustion engine cannot reach the operating temperature.

Over speeding is also a bad actor in fuel consumption. Vehicles are constructed to be utilized up to a certain speed, that is depending on their engine and power output. Using vehicles on too high speed results in all cases extra fuel consumption.

\subsection{Ambient parameters}

Ambient parameters have effect on fuel consumption as well. Intake air temperature could one parameter, but in the time of turbocharged and with intercooler equipped engines, its role is marginal. High external temperatures are mostly followed with the start-up of the cooling system that has a measureable effect on fuel consumption. In another end, if auxiliary heating is necessary, while ambient temperature is cold, then it has also an increasing effect on fuel consumption. Driving with the AC on generally adds extra load to the engine hence it consumes more fuel when operating. However, if driving at speed of over $80 \mathrm{~km} / \mathrm{h}$, use of airconditioning is better for fuel consumption compared to an open window as the latter creates aerodynamic drag, which is bad for fuel economy.

Table 2. Main influencers of vehicle fuel consumption

\begin{tabular}{|l|l|}
\hline \multicolumn{2}{|c|}{ Fuel consmuption influencers } \\
\hline Vehicle driven parameters & Usage related parameters \\
\hline weight & total runtime \\
gearbox & vehicle speed \\
engine type & severity of accelerations \\
electric motor type & number of brakings \\
vehicle type & over speeding \\
maintenance & driver style \\
engine oil & engine start-up \\
tires & short trips \\
\hline Road related parameters & Ambient parameters \\
\hline surface type & Intake air temperature \\
material & cold temperature \\
& extra warm temperature \\
& landscape profile \\
\hline
\end{tabular}

Landscape profile for any trip has huge impact in the achievable fuel economy of the vehicles. A test was 
conducted to measure the landscape effect on fuel consumption, it results [6] that there is measurable connection between the road landscape and the fuel consumption.

Table 2 summarizes main influencers of fuel consumption. As it is easy to recognize, vehicle related parameters are influencing the fuel consumption on long term mostly.

Road related parameters and ambient parameters are external from the vehicle point of view, they have to be recognized and if possible a decision should be made between alternatives. Usage related parameters are those where driver or automated vehicle can influence fuel consumption.

\section{Predicting of fuel consumption}

Ability to model and predict the fuel consumption is vital in enhancing fuel economy of vehicles and preventing fraudulent activities in fleet management. Fuel consumption of a vehicle depends on several internal factors such as distance, load, vehicle characteristics, and driver behaviour, as well as external factors such as road conditions, traffic, and weather. However, not all these factors may be measured or available for the fuel consumption analysis.

Predicting methods for fuel consumption are mainly focusing on vehicle data or handling transportations as a flow. Utilization of fleet management system interface [1], is an easy way to get data from the vehicle. This study utilizes various vehicle parameters like speed, total fuel consumption, distance travelled, total runtime for example.

Another approach is to measure vehicles on test bench and make predictive figures based on the experiences. A passenger car with diesel engine was measured according to the UDC test cycle. Results of this work shows that fuel consumption can measured with UDC cycle only with huge simplifications. A research was carried out to creating a simulation for prediction of mileage fuel consumption based on engine operational parameters, such as fuel consumption and effective power [4]. With a self-developed algorithm, the main goal was to determine instantaneous fuel consumption not only for constant but for variable velocities as well, and based on these simulate mileage fuel consumption. Measurement uncertainties was taken into consideration, but with them as well the fuel consumption of the measured vehicles was higher by 34.8 to $46 \%$ than the manufacturer given value.

Utilization of big data and data mining techniques is a utilized solution as well. In a research (5) the data acquisition was focusing on GPS data, authors proposed a solution that can estimate on a more accurate way and it is able to visualize energy consumption of vehicle based on analysis of vehicles' mobile and stationary activities. According to their proposal by adopting analytical concept of space-time path in time geography, they recommend methodology with that vehicle energy consumption and emissions can be estimated more accurately
Direction of vehicle routes can be a basis of fuel consumption estimation as well. In a case study [8], a method is presented that deal with fuel consumption and vehicle emissions of a single vehicle combined with a road network. Both are estimated and visualized with help of GPS data. Estimation accuracy of the utilized method reaches nearly $89 \%$. Different road segments typical fuel consumption is analysed as well to able to determine patterns and internal mechanisms.

During the investigation five machine-learning methods were compared to able to build up the best model based on historical data analysis and prediction. From the five investigated techniques the quantile regression was found as best suitable. It is a classical least square estimation extension [8].

An investigation [9] puts sampling time into the fuel consumption centre. Results of this study clearly shows that increasing sampling rate to 10 minutes results better fuel consumption prediction as a sampling rate of 1 minutes. Main influencers of fuel consumption is road slope, weight and speed of vehicle is determined. Random forest, supporting vector model and artificial networks are compared and according this study the differences in punctuality are negligible.

Most of the methodological approaches are investigating a part of the fuel consumption elements and do not handling the issue as a whole. Consumption predictions are reduced to conventional fuel management. In this approach focus is on the most complex vehicles: plug-in-hybrids and as method the aim is to combine all elements that have predictable and measurable effect on fuel economy [9].

A research focused on three different machine learning techniques to see their usability in fuel consumption prediction [10]. In their research paper it is presented the application of the chosen three techniques to as a fuel consumption predicting tool. The model was set on trucks for a large dataset. Random Forest (RF), Support Vector Machine (SVM), and Artificial Neural Network (ANN) models have been developed and their prediction was compared. In most of the cases the telematics data is the basis of fleet performance evaluation for fleet managers, and maintenance related decisions or drivers' education based on these as well.

Available vehicle data is standardized according to SAE J1939 regulation. Road characteristic data for the test was given by local authority database. Based on those data it was possible to develop a new fuel consumption model, that incorporates road parameters into the fuel consumption prediction, and in this way influence fleet managers. Ten-times cross-validation was carried out to let learn the neural network, random forest and support vector machine models. The methodological results of the research were that random forest outperforms slightly support vector machine and artificial neural networks with higher R2 and lower error level [11].

Artificial neural network was used for personal car fuel consumption prediction in a research [13]. As carbon-dioxide emission is in predict direct relationship with vehicles fuel consumption with fuel prediction the emission cold as well. Vehicles have to face with most 
of influencing parameters in urban areas. Based on these facts the test was carried out in an urban area. Main factors that influenced fuel consumption were speed of the vehicle, city zone and time within the day and within the week. Satisfactory prediction accuracy was reached with a single hidden layer artificial neural network having 10 neurons [13].

As it is summarized in Table 3, fuel consumption prediction methods are tested mainly random forest, support vector machine and artificial neural network for prediction, but no clear preference is to see. In most of the cases GPS coordinates and fuel consumption are basis of the calculations but several other data is used as input. To special aspects is worth to mention: 10-minute sampling time is proposed and road segmentation could be a value added input data for the prediction.

Table 3. Fuel Consumption prediction summary

\begin{tabular}{|r|l|l|l|l|l|}
\hline Nr. & $\begin{array}{c}\text { Artificial } \\
\text { Intelligence used }\end{array}$ & $\begin{array}{c}\text { Engine } \\
\text { type }\end{array}$ & $\begin{array}{c}\text { Vehicle } \\
\text { type }\end{array}$ & \multicolumn{1}{|c|}{ Data } & Speciality \\
\hline & & diesel & HD & $\begin{array}{l}\text { speed, fuel } \\
\text { consumption, } \\
\text { distance, runtime }\end{array}$ & \\
\hline 4 & & diesel & PC & & \\
\hline 5 & data mining & diesel & & $\begin{array}{l}\text { GPS, energy } \\
\text { consumption }\end{array}$ & \\
\hline 8 & quantile regression & gasoline & & $\begin{array}{l}\text { GPS, fuel } \\
\text { consumption }\end{array}$ & road segmentation \\
\hline 9 & RF, SVM, ANN & hybrid & & & sampling time \\
\hline 10 & RF, ANN, SVM & diesel & & & \\
\hline 11 & ANN, SVM, RF & & & & \\
\hline 13 & ANN & & & & \\
\hline
\end{tabular}

\section{Refuelling}

Prediction of fuel consumption is the first step to calculate the refuelling need of the vehicle and as next step extend it to refuelling optimization. There ae only a few researches that deals with the problems of refuelling.

One of the researches that aims to increase the effectiveness of refuelling decision instead of handling the refuelling as a technical prediction. As it is in other sources as $[15,16,24]$ it is mentioned that pricing has an important role in refuelling decision problems. This study puts in the focus of the examination the viability of utilization a refuelling plan that aims to keep fuel expenses as low as possible for heavy-duty vehicles. They proofing the idea, that if refuelling happens more often but in cheaper fuel stations and with this method not only the lower price is beneficial but the lower weight of the vehicle causes lower fuel consumption.

In the current study, when the optimized refuelling strategy is calculated, the weight of the fuel is taken into consideration which leads to more frequent stops but also a lower fuel consumption. To test this strategy, a fuel consumption model was created with dynamic programming algorithm. Fuel consumption of the heavyduty vehicle is calculated with the help of a recorded drive cycle. Dynamic programming algorithm is the responsible to decides whether to refuel at a specific fuel station in the function of fuel price of the station and the distance to upcoming stations. Main statement of the research is in one side there is a small amount of both money and fuel saving in most of the cases, but the in many cases, the predictability of the model makes its utilization at least questionable [12].

Refuelling prediction of electric vehicles is a much sharper topic, as the full load of a battery is around in that distance with which with a traditional internal combustion engine the driver starts to think that it is high time to refuel the vehicle. A research presents results of route planning for electric vehicles in a road network [14]. Main driver of route planning is in most of the cases to find the fastest way. It is ordinary for traditional vehicles with fuel, while the refuelling time is negligible compared to travelling time. The situation differs in case of electric vehicles: this energy is enough for shorter trips and refuelling time could take much longer. Furthermore, recharging prices of electric vehicles follows different standards than the pricing for conventional vehicles. The research propose a solution how to find balance between travel time and electric vehicle price of travel.

A study was focusing on the special requisites of battery electric vehicles, as they require different driver information systems. According to the anticipation of the researchers, a new highly integrated and networked information system is vital for electric vehicles that combines central car systems, drivers' behavioural data and parameters of the environment. Proposal of the research is to introduce an OEM-independent cruising range prediction system, which combines measurement and GIS-system based calculations on the road. The proposed model uses as main input parameters the most relevant range-affecting variables as driving style of the driver, ambient temperatures, battery charge status, navigational data, plan of energy consumption, and prediction of the route distance. Based on this data the optimal range can be managed.

Vehicle system used in the research consists of an optional on-board unit with data acquisition and measurement opportunity and communication device that offers navigation, support the power management. A self-learning algorithm is the heart of the model, as an aggregation feature that collect all data from environment and vehicle. It is responsible for propose charging or battery swapping stations on the planned route, which will then be passed on to a reservation management system, making sure the driver can enjoy a maximum of comfort and peace-of-mind on his or her journey. [18]

One of the neuralgic points of electric vehicles is the range uncertainty. It hindrance the extensive dissemination of this vehicles. Electric vehicles owners and driver stress on driving range can be reduced if vehicle's energy consumption is better understood. A research work [19] propose a predictive strategy for energy needs estimation of an electric vehicle. During the estimation vehicle related parameters and the topology data of the roads, and actual traffic conditions were used. In the model the energy consumption was represented with a macroscopic model. Basis of that was aggregated real-time data from web providers' maps. Model of the road network was an adaptation of a weighted direct graph. 


\section{Conclusions}

As conclusion of this paper is can be stated, that plug-in-hybrid vehicles are the most complex ones at this stage of the technology. Our research aims to build fuel economy and refuelling prediction of these complex vehicles. Our goal is to incorporate all external and internal parameters that could have measurable and predictive effect on fuel consumption and refuelling of the vehicle. Vehicle related parameters have the lowest prompt effect on fuel consumption but they could be featured with tendencies. Road and ambient related parameters can be detected with different sensors, and signals should be processed within the vehicle. Usage related parameters could be reached via vehicle CAN system. A good mix of these signals and data should be the basis of the refuelling decision extended with refuelling stations data.

The research reported in this paper was supported by the Higher Education Excellence Program of the Ministry of Human Capacities in the frame of Artificial Intelligence research area of Budapest University of Technology and Economics (BME FIKP-MI/FM).

\section{References}

1. A. Viswanathan, 'Data driven analysis of usage and driving parameters that affect fuel consumption of heavy vehicles', Dissertation, http://www.divaportal.org/smash/record.jsf?pid=diva2\%3A634988\& dswid=851 (2013)

2. K. Barry, Rigid Roads Can Reduce Fuel Consumption, VIRED, Gear (2012)

3. A. Geiger A. Holló, A Thernesz, R. Durgo S. Czibor, L. Bartha, P. Gergó Chemically Stabilized Rubber Bitumen, EEC, 1-8. (2012).

4. W. Gołębiewski., T. Stoeck TEKA. Commission of Mot. \& Energ. in Agriculture - 2014. 14, 3, 17-24 (2014)

5. Z. Kan, L. Tang, M.P. Kwan, X. Zhang. Int. J. Environ. Res. Public Health 2018, 15, 566; (2018) DOI:10.3390/ijerph15040566 (2018)

6. O. Franzese, Freight Trucks, 8 (2011) https://info.ornl.gov/sites/publications/files/Pub3338 6.pdf

7. Hybrid and Battery Electric Vehicles, http://autocaat.org/Technologies/Hybrid and Battery _Electric_Vehicles/

8. X. Zhigang W. Tao, E. Said, Z. Xiangmo, Q. Xiaobo, Computer-Aided Civil and Infrastructure Engineering,. 33, pp. 209, (2018.)
9. H. Almér, Machine learning and statistical analysis in fuel consumption prediction for heavy vehicles in KTH, Sweden, (2015)

10. F. Perrotta,, T. Parry, L. Neves,.. IEEE Conference on Big Data (2017). DOI: 10.1109/BigData.2017.8258382.2017

11. S. Wickramanayake, D. Bandara, Fuel consumption prediction of fleet vehicles using Machine Learning: A comparative study. 90-95. 10.1109/MERCon.2016.7480121. (2016).

12. J. Telberg Fixed Route Optimal Refuelling Plan. KTH Royal Institute of Technology. www.divaportal.org/smash/get/diva2:957311/FULLTEXT01.p df

13. B. Predić, M. Madić, M. Roganović, M. Kovačević, D. Stojanović, Facta Universitatis, Series: Automatic Control and Robotics, 1(2), 105-116. Retrieved from http://casopisi.junis.ni.ac.rs/index.php/FUAutContRo b/article/view/1597 (2016).

14. M. Højsleth, A. T. Lau, A. Strandfelt, Personalized Route Planning with Recharging for Electric Vehicles.

https://projekter.aau.dk/projekter/files/239555254/art icle.pdf

15. A. Török, A. Török, F. Heinitz, Transport and Telecommunication Journal. 15(4), 292-298. https://doi.org/10.2478/ttj-2014-0025 (2014).

16. R. Ildarkhanov, Periodica Polytechnica Transportation Engineering. Onlinefirst, 7 DOI 10.3311/PPtr.10553 (2018)

17. Z. Szalay, T. Tettamanti, D- Esztergár-Kiss, I. Varga, C. Bartolini, Periodica Polytechnica Transportation Engineering, 46(1), 29-35. DOI: 10.3311/PPtr.10753. (2018)

18. P. Conradi, P. Bouteiller, S. Hanßen, Advanced Microsystemsfor Automotive Applications, Heidelberg:Springer,. 269-277, (2011)

19. G. De Nunzio, L. Thibault, A. Sciarretta, Intelligent Transportation Systems (ITSC) 2017 IEEE 20th International Conference, 1-7, (2017)

20. A. Rimkus, J. Matijošius, M. Bogdevičius, Á. Bereczky, Á. Török,. Energy, 152, 640-651. (2018)

21. I. Barabás. Fuel, 109, 563-574. (2013)

22. D. Dobrowolski, P. Droździel, R. Madleňák, I. K. Rybicka, D. Siłuch, Advances in Science and Technology. Research Journal, 12(3). (2018)

23. R. Madleňák, L. Madleňáková, D. Hoštáková, P. Drozdziel, Á. Török, Advances in Science and Technology. Research Journal, 12(2). (2018).

24. L. Hansut, A. David, J. Gasparik. Bussines Logistic In Modern Management. 29-42. (2017) 